\title{
CONSUMERS' PERCEIVED RISK AND ITS EFFECT ON ADOPTION OF ONLINE BANKING SERVICES
}

\author{
${ }^{1}$ Fereshteh Farzianpour, ${ }^{2}$ Mahsa Pishdar, \\ ${ }^{3}$ Masoumeh Danesh Shakib and ${ }^{4}$ Mohammad Reza Seyyed Hashemi Toloun \\ ${ }^{1}$ Department of Health Management and Economics, \\ School of Public Health, Tehran University of Medical Sciences, Tehran, Iran \\ ${ }^{2}$ Department of Production and Operation Management, Allameh Tabatabaii University, Tehran, Iran \\ ${ }^{3}$ Department of Management, Sciences and Research Branch of Islamic Azad University, Tehran, Iran \\ ${ }^{4}$ Department of Management, Sohrevardi Institution, Qazvin, Iran
}

Received 2013-11-08, Revised 2013-11-12; Accepted 2013-11-23

\begin{abstract}
Although online banking services have gained a lot of attention, many consumers are still not willing to use them. Since online banking services can be a competitive advantage for banks, it is useful to know the core factors affecting the use of online banking services. This study sheds light on different aspects of consumers' perceived risk to analyses the influence of total perceived risk and consumers' willingness to embrace innovation on online banking services adoption. Results of the study show that the consumer's total perceived risk and willingness to accept innovation both have a direct effect on online banking services adoption, while willingness to adopt innovation has no significant influence on the consumer's total perceived risk. Meanwhile, it seems that social perceived risk cannot increase the consumer's total perceived risk. Beside these, the extent of other consumers' perceived risks is forecasted by the execution of a neural network. This forecasting helps to understand whether other consumers that have same feeling as members of study society are willing to adopt online banking services or not.
\end{abstract}

Keywords: Perceived Risk, Innovation Adoption, Online Banking Services, Neural Network

\section{INTRODUCTION}

Competitive advantage has a lot of importance in different industries such as the banking industry. It is agreed that online banking can improve the quality of banks' services and reduce the operational costs. The number of banks that are trying to gain this competitive advantage is increasing day by day. Online banking is a technology that represents a variety of different services, ranging from the common automatic teller machine services and direct deposit to automatic bill payment, electronic transfer of funds and computer banking (Kolodinsky et al., 2004). If the protection of consumers' information can be strengthened, the bank can benefit a lot of providing online services (Lee et al., 2013a).
It is obvious that many consumers are not willing to use online banking services in spite of the banks' investments and efforts in this domain. The bank service providers play an important role in encouraging customers to use these kinds of services. A lot of surveys showed that it is possible to reduce banking network costs in this way. Daniel (1999) is probably one of the firsts to show banks can improve their efficiency through technology adoption. The author showed that corporate vision of the future in which the environment becomes more competitive can propel it to use online services. This has made it clear to some researchers like Bauer and Hein (2006) and Lee (2009) that recognizing effective factors on adoption and usage of these services is really important.

Corresponding Author: Fereshteh Farzianpour, Department of Health Management and Economics, School of Public Health, Tehran University of Medical Sciences, Tehran, Iran Tel: +982144648943 
By a simple review of the related literature, one can absorb that innovation adoption from consumers and their perceived risk are important factors in online banking succession. Since it is obvious that not all of the consumers are willing to take these services at a time, the power of understanding the risk of using these services and innovation adoption are some of the factors that push Internet users towards online shopping. So, the main objective of this study is to investigate the effects of such factors on the usage of these kinds of services. Ranking various aspects of risk perception by paying attention to their influence on the use of online banking is also important too while chasing the target mentioned above. This has encouraged us to investigate the effects of such factors on MELLAT bank consumers in Iran, In order to make bank managers capable of understanding the unique concerned market situation; 384 depositors have been selected randomly to study hypotheses. In addition, it can be helpful to understand whether other depositors who are in the similar situation as members of the study sample are willing to adopt online banking services or not. By focusing on this result, it can be possible to predict others' behavior.

It is obvious that online banking is a mutual relationship between the bank and the depositor, which is based on their common interest. The results of this study can be effective in providing online banking services in macro policy making of banks in Iran or banks that are exposed to the same conditions.

Hypotheses that can be helpful in getting these objectives are as follows.

Perceived risk can affect the consumer's decision whether to use online services or not. It has been specified that consumer feels the risk of different parts of usage of online services and try to prevent it (Hong and $\mathrm{Yi}, 2012$ ) therefore:

Hypothesis 1: The depositor's total perceived risk can decrease their willingness to adopt online banking services.

There are various aspects of risk perception that give rise to the extent of consumers' perceived risk about using online banking services. One of these aspects is performance risk, which talks about consumers' worries about the product or service level of performance in relation to expectations (Nicolaou et al., 2013). Performance risk depends on the consumers' knowledge and cognitive capabilities about a special product or service. Asymmetry of information in online banking and the lack of personal communication prevent testing the service in a correct manner and lowers confidence
(Littler and Melanthiou, 2006). That is why some banks try to transfer correct information through special websites and let them try such services before using those (Cunningham et al., 2005). By this one can assume that:

Sub-Hypothesis 1.1: Consumers' performance risk perception enhances their risk understanding about the adoption of online banking services.

Consumers believe that security risk is related to the threat of losing money. Surveys have shown that security risk is one of the important factors that can have influence on adoption of online banking services. The gap between the perceived security of a technology and its real security level can affect behavior of people (Huang et al., 2011). The success of online banking service adoption is threatened by lack of awareness and incorrect perceived knowledge about information and money security (Huang et al., 2010) so:

Sub-Hypothesis 1.2: Consumers' security risk perception increases their risk understanding about adoption of online banking services.

Social situations can affect the adoption of online banking services. Consumers belong to different social environments. They are surrounded by people that each has their own ideas about these kinds of services. People transfer their ideas and experiences to each other (Littler and Melanthiou, 2006), they tend to pay more attention to social relationships and others' experiences when there is a lot of opposition to a new technology. Controlling depositors' behavior is much more important in this situation. A concrete example is related to social networks. Although there are some risks, many people share their information using these networks. They try to optimize the risk that are encountered with and the benefits ahead (Lee et al., 2013a; 2013b). Banks should carefully direct consumers' minds in order to encourage them. That is why it seems reasonable to assume that:

Sub-Hypothesis 1.3: Consumers' social risk perception increases their risk understanding about adoption of online banking services.

The Internet has a great effect on how things are done. It can provide its user with information in a flash. But one should consider this matter that learning how to work with a new technology can be time consuming. This can get a lot of importance when providing service with the help of internet is low. Also there is a risk that the transaction would not be done correctly (Ruiz-Mafe et al., 2009). It can therefore be assumed that: 
Sub-Hypothesis 1.4: Consumers' time loss risk perception increases their risk understanding about adoption of online banking services.

Another important obstacle in the adoption of online banking services is violations of consumers' privacy and their confidential information (Li, 2012). Surveys have shown that consumers are concerned that others would obtain their personal information. Farzianpour et al. (2011a) users like to control all the aspects of gathering their personal information while using these services. Farzianpour et al. (2011b) this has made it a real challenge for banks to provide information security ( $\mathrm{Li}$, 2012). Various researchers have paid attention to this and even investigated governments' behaviors against this concern. Wu et al. (2011) explored the online privacy regulations and their similarity in two countries, the United States and China. Results showed that American legislative initiatives are more comprehensive and integrated than those of their Chinese counterparts. In China, there was no specific right of privacy specified in dedicated legislation until recently. This important matter makes this hypothesis:

Sub-Hypothesis 1.5: Consumers' privacy risk perception gives augmentation to their risk understanding about the adoption of online banking services.

In addition, one can assume that:
Hypothesis 2: Consumers' risk perception has a negative effect on their tendency to use online banking services.

A consumer'sinnovation assent is about consumers characteristics. Some people can adopt new ideas and technologies much faster than others without having any related experiences. This has caused some researchers to study how to encourage people to accept new things. Kolodinsky et al. (2004) studied the theories of technology adoption to the acceptance of e-banking technologies. They examined whether and how the characteristics that describe the adoption of new innovations are related to consumer adoption of online banking technologies. They concluded that measures of personal characteristics and measures of innovation diffusion can determine speed and level of adoption. Li (2013) noticed that lifestyle orientations are other powerful cue to the admission of some new technologies. It seems that people willingness to innovation adoption increases their propensity to use online banking services. This enhances their risk tolerance so:

Hypothesis 3: Consumers' innovation adoption increases consumers' tendency to use online banking services.

Hypothesis 4: Consumers' willingness to innovation adoption decreases their risk perception about using online banking services.

By obtaining these hypotheses, the basic framework of this study is set as is shown in Fig. 1.

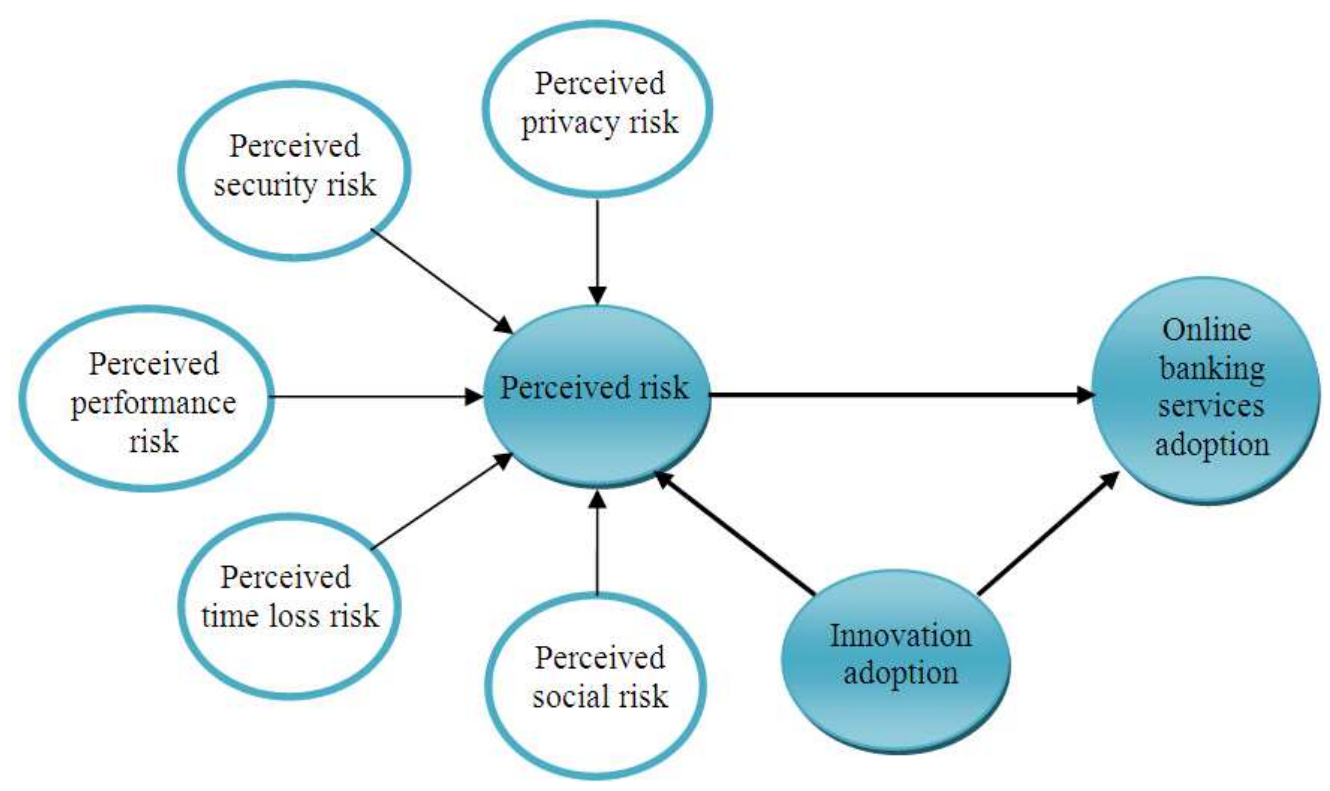

Fig. 1. The basic model of current study 


\section{LITERATURE REVIEW}

According to one definition, a bank is an institution for maintaining funds, raising additional funds and granting $f$ unds to credit to the people who need financial resources Investopedia, 2013. By another definition, a bank collects the funds wandering and not in use by their owners and invests them in various sectors or grant facility will such as promoting environmental sustainability that is considered by the (WB, 2013). In these two definitions, major activities of a bank are considered to be collecting deposits and making decisions about how to use it. But other banking operations-in particular, new functionalities such as online services-must be considered. So, a bank can be defined as a commercial entity that collects people's surplus funds and attempts to use and allocate them in an optimal way for a country's economic and credit policies. According to this definition, banking is the function and the role that banks play. So, banks traditional functions and the role that they play according to the evolution of technology should be considered simultaneously (Haubrich and Santos, 2005).

In electronic banking, information is available in digital format; e-banking means banking operations through centralized computer systems and networks which are not limited in time and space. By e-banking it is possible to provide consumers with access to banking services, through the use of safe intermediate and without physical Presence (Yousafzai et al., 2003).

In compare with traditional banking, electronic banking while providing comprehensive banking services with good quality, has the idea of development based on customer satisfaction and increasing revenue based on providing services that will receive a commission (Beheshti et al., 2012).

Risk is a function of the magnitude or extent of goals that a person tries to reach and also the seriousness of the atonement that one must endure while not reaching them (Mitchell, 1999). Stone and Winter (1987) defined risk as an individual expectation of potential losses. The higher probability of a loss, the more risk is perceived by the individual.

Bauer (1960) focused on perceived risk (subjective) rather than actual risk (objective). A typical consumer has limited information and a semi-reliable memory; the goods and services have been tested a few times by them. Therefore, it is often impossible tomakean accurate assessment of risk. Even if the consumer is able to calculate related risks, the calculated risks are not real risks that can drive the consumer behavior, but subjective opinion. So, to measure theperceivedrisk, these limitations should be noted (Mitchell, 1999). Perceived risk is considered a fundamental concept of consumer behavior and is often used to explain customers' risk perceptions and reduction methods (Mitra et al., 1987; Shin, 2010). Perceived risk significantly guides consumer behavior, because people wish to avoid making mistakes (Mitchell, 1999). The magnitude of a perceived risk depends on many factors, such as how important the target is and how serious the possible consequences of a mistake are (Cox, 1967; Dowling and Staelin, 1994; Lee, 2009).

Risk perception has been considered by both researchers (Grewal et al., 1994) and Practitioners (Farquhar, 1994). This domain of study has been used in a wide range and providing different goods and services, such as food industry technology, dental services, banking services. There is no doubt that a purchase decision must lead to satisfaction, so positive results are expected and if there are negative consequences, it is possible that expected level of satisfaction will not be achieved (Yoon, 2010). That is why Consumer risk perception is important in marketing. It is believed that innovation can increase consumer's satisfaction level. Innovation is a process in which a preferred option, or a different procedure or product, is selected in order to make it practical and the shortcomings of the product or procedure are fixed or improved upon. Innovation is an attempt to replace new production models with old ones or provide new products and services to market. That is why it seems that innovation adoption can affect the adoption of consumers' online banking services. But there must be a consumer centric perspective about this process (Vize et al., 2013).

\section{METHODOLOGY}

In order to study total perceived risk, a regression analysis has been done by focusing on perceived privacy risk, perceived security risk, perceived performance risk, perceived time loss risk and perceived social risk-which are shown above in Fig. 1. On the other hand, perceived risk affection on the extent of online banking services adoption is investigated. Innovation adoption is the last variable that is considered in this study. Using regression analysis, one can see whether innovation adoption affects perceived risk and also the extent of using online banking services or not. Each variable and its relationship with other variables are described in this study. So, this study can be seen as a descriptive and analytical study. 
All customers of Mellat banks' branches that have received a password and user ID to access the bank's online banking system have to make up the study society. The number of people that have the chance to be in the sample is more than 616923 until the 20th of May, 2011. 384 people has been selected by chance and using the table of Krejcie and Morgan in order to make the sample. It should be mentioned that the people in the study society were classified based on the locations of Mellat bank's branches that they have received their user ID and password from.

Data was collected using anelectronic questionnaire based on the questionnaire used in the Ruiz-Mafe et al. (2009). However, the basic questionnaireis localized in order to be suitable to be used in Iran. The questionnaire has been emailed to 6000 people that belong to the study society; only 400 people have replied this email. The rate of questionnaire's reply is about $7 \%$, which is acceptable for electronic questionnaires.

It is known that reliability is very important in dealing with questionnaires. It helps the researcher to study what he really means. If the questionnaire cannot be shown to be reliable, there is no discussion that the results of the study are not correct. Cronbach salpha is used to determine the reliability of constructs. Besides calculating the total alpha for the questionnaire, Cronbach`s alpha is calculated for each construct that is considered in this study. Table 1 shows the total alpha value and Table 2 demonstrates the alpha value for each construct. Since all of the alpha coefficients are greater than 0.7 , one can say that the questionnaire has satisfactory reliability.

Another important matter is the validity of the questionnaire. Content validity and construct validity are paid attention to in this study. The questionnaire was presented to five experts in the field of electronic banking, all of whom found it suitable to be used. This shows appropriate content validity of the questionnaire. Since the overall structure of the research constructs and variables have been used in previous researches, the present study uses confirmatory factor analysis to verify the basic model.

The study analyzed data by using a variety of statistical methods. Kolmogorov-Smirnov test is used to determine data normality status. The Spearman is designed to investigate the correlation between the constructs of present study. Structural Equation Modeling (SEM) is also carried out to study hypothesis by considering the maximum likelihood method.
Table 1. Total alpha value

\begin{tabular}{|c|c|c|}
\hline \multicolumn{2}{|c|}{$\begin{array}{l}\text { Total number of questions } \\
\text { in the questionnaire }\end{array}$} & Total Cronbach`s alpha \\
\hline \multicolumn{2}{|l|}{22} & $0 / 7048$ \\
\hline & \multicolumn{2}{|c|}{ Table 2. Alpha value for each construct } \\
\hline Row & Construct & Cronbach`s alpha \\
\hline 1 & Perceived performance risk & $0 / 8968$ \\
\hline 2 & Perceived security risk & 0/7949 \\
\hline 3 & Perceived social risk & $0 / 8360$ \\
\hline 4 & Perceived time loss risk & $0 / 8470$ \\
\hline 5 & Perceived privacy risk & $0 / 7512$ \\
\hline 6 & Innovation adoption & $0 / 7358$ \\
\hline
\end{tabular}

\subsection{Data Analysis}

A demographic analysis can provide useful information about respondents of the questionnaire. Table 3 shows different categorized information about respondents.

As it is shown, most of the respondents are men. The age of the $43.25 \%$ of the respondents is 25 to 34.278 respondents are married and more than half of the respondent's educational degree is bachelor. In order to assess the use of online banking service in Iran, likert type questions were presented to sample members. 378people responded to these questions that are observable at the last part of Table 3. The answers can measure the core of internet banking services in Iran. As it turns out, account review and receiving statements have the greatest mean score among the three.

\subsection{Kolmogorov-Smirnov Test}

Kolmogorov-Smirnov test can determine the normality status of the data distribution in this study. Accordingly, if the test is significant, then the data distribution is not normal and the null hypothesis will be rejected. The result of the test indicates that the significance level for all constructs is less than 5\%; that is why one can say that data distribution is normal. Table 4 shows these results.

\subsection{Spearman Test}

Before paying attention to Structural Equation Modeling, it is possible to investigate the relationships between study variables by using the correlation coefficient. Since the questionnaire and Likert type questions are concerned in this study, the Spearman Correlation Coefficient is used to study the relationships between constructs. The results of the Spearman test are indicated in Table 5. 
Table 3. Demographic analysis results of respondents

\begin{tabular}{llll}
\hline Gender & Frequency & Percentage & Cumulative (\%) \\
\hline Man & 283 & $70 / 75$ & $70 / 75$ \\
Woman & 117 & $29 / 25$ & 100 \\
Age & & & $5 / 75$ \\
Under 24 & 23 & $5 / 75$ & 49 \\
$25-34$ & 173 & $43 / 25$ & $79 / 5$ \\
$35-44$ & 122 & $30 / 5$ & $95 / 75$ \\
$45-54$ & 65 & $16 / 25$ & $99 / 5$ \\
$55-64$ & 15 & Mar-75 & 100 \\
More than 65 & 2 & $0 / 5$ & $69 / 5$ \\
Marital status & & & 100 \\
Married & 278 & $69 / 5$ & $54 / 5$ \\
Unmarried & 122 & $30 / 5$ & 94 \\
Level of education & & & 100 \\
Diploma & 164 & 41 & The mean scores \\
Bachelor & 212 & 53 & $4 / 4$ \\
Masters & 24 & 6 & $3 / 9$ \\
Total & 400 & 100 & $3 / 6$ \\
On-line banking service & & & \\
Account review and receiving statements & & & \\
Funds transfer & & & \\
Bill payment services & & & \\
\hline
\end{tabular}

Table 4. $\mathrm{Z}$ of Kolmogorov-Smirnov test and significance level for each construct of the study

\begin{tabular}{lll}
\hline Construct & Z of Kolmogorov-Smirnov test & Significance level \\
\hline Perceived security risk & $4 / 268$ & $0 / 000$ \\
Perceived performance risk & $4 / 019$ & $0 / 000$ \\
Perceived social risk & $5 / 706$ & $0 / 000$ \\
Perceived time loss risk & $5 / 085$ & $0 / 000$ \\
Perceived privacy risk & $4 / 421$ & $0 / 000$ \\
Total perceived risk & $5 / 999$ & $0 / 000$ \\
Innovation adoption & $3 / 191$ & $0 / 000$ \\
On-line banking service adoption & $3 / 298$ & $0 / 000$ \\
\hline
\end{tabular}

Table 5. Results of spearman test

\begin{tabular}{lllll}
\hline First variable & Second variable & $\mathrm{N}$ & Correlation coefficient & Significance level \\
\hline Total perceived risk & Perceived security risk & 400 & $0 / 420$ & $0 / 000$ \\
Total perceived risk & Perceived privacy risk & 400 & $0 / 488$ & $0 / 000$ \\
Total perceived risk & Perceived social risk & 400 & $0 / 158$ & $0 / 001$ \\
Total perceived risk & Perceived time loss risk & 400 & $0 / 464$ & $0 / 000$ \\
Total perceived risk & Perceived performance risk & 400 & $0 / 411$ & $0 / 000$ \\
Total perceived risk & Innovation adoption & 400 & 0 & $0 / 000$ \\
Total perceived risk & On-line banking service adoption & 400 & 0 & $0 / 000$ \\
Innovation adoption & On-line banking service adoption & 400 & $0 / 298$ & $0 / 000$ \\
\hline
\end{tabular}

As it is clear, apart from the relations of total risk perception-innovation adoption and total risk perception, online banking service adoption and total risk perception-the correlation between the rest of the constructs is positive. It should be mentioned that the correlation between total risk perception-innovation adoption and total risk perception, online banking service adoption and total risk perception-is significant and negative. It means that risk perception has a negative effect on innovation adoption and online banking service adoption. The extent of this effect is as much as the correlation coefficient that is shown in Table 5. The 
results of using this test show that concerned variables are correlated. Structural Equation Modeling can get much more exact results.

\subsection{Structural Equation Modeling}

Structural Equation Modeling is used to examine the hypotheses of this study. The path coefficient and t-value can be obtained by usage of LISRELL software (The version of LISREL that is used here is 8.5). The effects of variables can be compared by considering the path coefficient. If the t-value is 2 or $\leq-2$ then the path coefficient is acceptable. Otherwise it is rejected. Hypotheses are tested at the 95\% confidence level. Table 6 illustrates the test results.

The calculated t-value for sub-hypothesis 1.3 and hypothesis 4 is less than 2, so the two concerned paths are not statistically significant. Therefore, social risk perception does not have a significant effect on adoption of online banking services adoption. In addition, the effect of consumers' innovation adoption on perceived risk of online banking services is not significant. This means that sub-hypothesis 1.3 and hypothesis 4 are not acceptable. But all of the other calculated t-values are 2 or $\leq-2$. So, the rest of the path coefficients are significant. That is why the rest of the hypotheses cannot be rejected. It is noteworthy that the path coefficient that belongs to hypothesis 2 is negative. It means that consumers' risk perception has significant negative effect on online banking services adoption as is found by the usage of the Spearmen test. But the other path coefficients are positive. So the effects that are concerned in subhypothesis 1.1 , sub-hypothesis 1.2 , sub-hypothesis 1.4 , sub-hypothesis 1.5 and hypothesis 3 are positive and statistically significant. These results make the base study model to transform in the way that is shown in Fig. 2. Relationships that are not significant are shown with dashes. Results show that respondents in the study are not affected by experiences and attitudes of the people around them and this cannot increase their perceived risk. Moreover, respondents' willingness to embrace innovation does not reduce the risk perceived by them.

\subsection{Fitting Indexes of the Model}

The fit indexes for a model can be obtained by comparing the estimated covariance matrix for the population and the covariance matrix for the sample. Although, there are different indexes that can be paid attention to, Root Mean Square Error of Approximation (RMSEA), Normal Fit Index (NFI), Non-Normal Fit Index (NNFI), Comparative Fit Index (CFI) are considered in this study. Table 7 shows the result of studying these indexes.

By comparison of the base amount and the calculated amount, it turns out that the model is fit.

\subsection{Rating of Perceived Risk Dimensions}

It is possible to rate dimensions of perceived risk by considering structural equations (Standardized coefficients). The constructs' effects on the formation of risk perception can be determined according to the obtained absolute value of the coefficient. The rating of perceived risk dimensions is given in Table 8. Based on the results, perceived privacy risk has the most effect on formation of total risk, while perceived social risk has the least effect. These results can be used for strategic planning and priorities identification; it is clear that to reduce the risk perceived by customers, perceived privacy risk should receive the highest consideration.

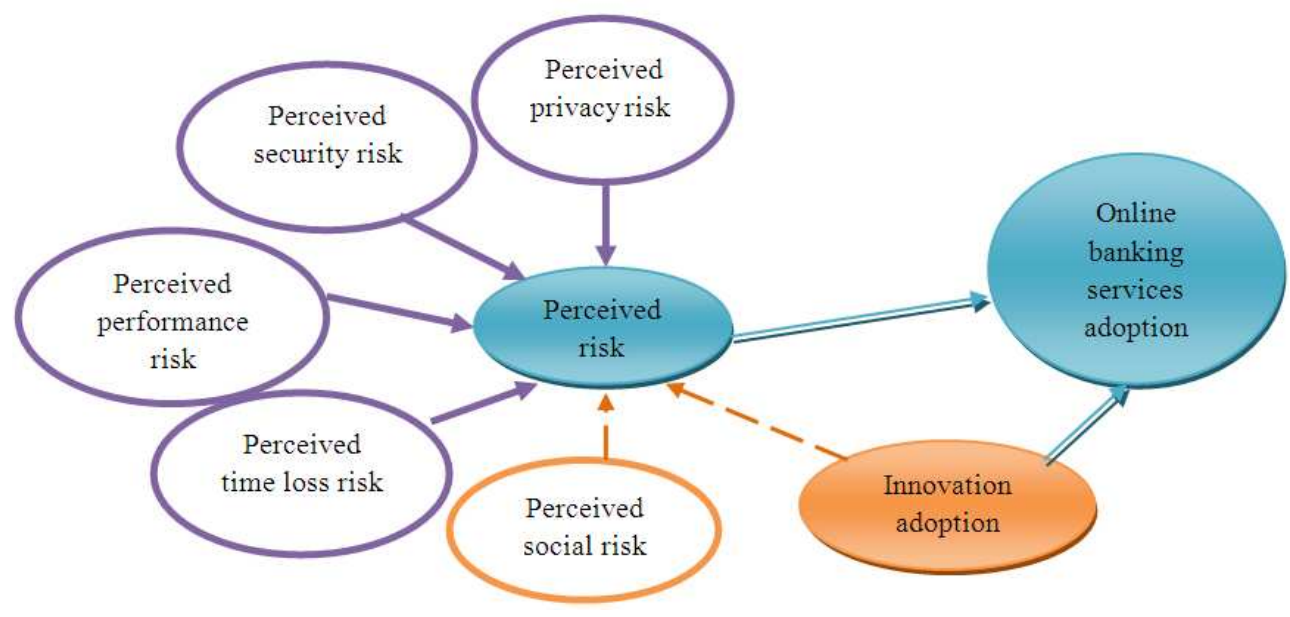

Fig. 2. Final model of the study 


\begin{tabular}{|c|c|c|c|c|c|c|c|c|c|c|c|c|c|c|c|c|c|c|c|c|c|c|c|}
\hline & Q1 & Q2 & Q3 & 04 & 05 & 06 & Q? & $Q 8$ & $Q 9$ & Q10 & Q11 & Q12 & Q13 & Q.14 & Q15 & Q16 & Q17 & Q18 & Q19 & Q20 & Q21 & Q22 TOTAL & TOTAL \\
\hline & 0 & 7.00 & 3.00 & 7.00 & 1.00 & 1.00 & 5.00 & 7.00 & 3.00 & 7.00 & 7.00 & 5.00 & 3.00 & 3.00 & 3.00 & 1.00 & 3.00 & 1.00 & 1.00 & 9.00 & 3.00 & $7.00 \quad 7.00$ & 6.211 \\
\hline & & 7.00 & 3.00 & 3.00 & 3.00 & 1.00 & 1.00 & 7.00 & 7.00 & 7.00 & 7.00 & 3.00 & 1.00 & 3.00 & 3.00 & 1.00 & 3.00 & 1.00 & 3.00 & 9.00 & 3.00 & $3.00 \quad 5.00$ & 5.180 \\
\hline & 9.00 & 7.00 & 1.00 & 3.00 & 7.00 & 100 & 7.00 & 3.00 & 3.00 & 5.00 & 5.00 & 7.00 & 3.00 & 3.00 & 5.00 & 7.00 & 7.00 & 3.00 & 5.00 & 3.00 & 7.00 & $7.00 \quad 3.00$ & 3.149 \\
\hline & 7.00 & 5.00 & 3.00 & 7.00 & 1.00 & 3.00 & 5.00 & 9.00 & 1.00 & 7.00 & 5.00 & 5.00 & 3.00 & 3.00 & 3.00 & 3.00 & 1.00 & 1.00 & 1.00 & 7.00 & 3.00 & $5.00 \quad 7.00$ & 6.622 \\
\hline & 3.00 & 7.00 & 3.00 & 5.00 & 5.00 & 3.00 & 3.00 & 5.00 & 5.00 & 7.00 & 7.00 & 3.00 & 1.00 & 1.00 & 1.00 & 3.00 & 1.00 & 1.00 & 3.00 & 7.00 & 3.00 & 7.003 .00 & 3.462 \\
\hline & 7.00 & 9.00 & 1.00 & 3.00 & 3.00 & 1.00 & 7.00 & 3.00 & 3.00 & 5.00 & 3.00 & 7.00 & 3.00 & 3.00 & 5.00 & 7.00 & 7.00 & 1.00 & 3.00 & 5.00 & 7.00 & $9.00 \quad 3.00$ & 3.180 \\
\hline 1 & 7.00 & 7.00 & 3.00 & 7.00 & 1.00 & 1.00 & 5.00 & 7.00 & 3.00 & 7.00 & 5.00 & 7.00 & 3.00 & 3.00 & 5.00 & 3.00 & 7.00 & 3.00 & 5.00 & 3.00 & 7.00 & $7.00 \quad 3.00$ & 3.276 \\
\hline & 3.00 & 7.00 & 3.00 & 3.00 & 3.00 & 1.00 & 1.00 & 7.00 & 7.00 & 7.00 & 5.00 & 5.00 & 3.00 & 3.00 & 3.00 & 3.00 & 1.00 & 1.00 & 1.00 & 7.00 & 3.00 & $5.00 \quad 7.00$ & 6.626 \\
\hline & 9.00 & 7.00 & 1.00 & 5.00 & 7.00 & 1.00 & 7.00 & 3.00 & 3.00 & 5.00 & 7.00 & 3.00 & 1.00 & 1.00 & 1.00 & 3.00 & 1.00 & 1.00 & 3.00 & 7.00 & 3.00 & $7.00 \quad 3.00$ & 3.160 \\
\hline & 7.00 & 5.00 & 3.00 & 7.00 & 1.00 & 3.00 & 5.00 & 9.00 & 1.00 & 7.00 & 3.00 & 7.00 & 3.00 & 3.00 & 5.00 & 7.00 & 7.00 & 1.00 & 3.00 & 5.00 & 7.00 & $9.00 \quad 3.00$ & 3.872 \\
\hline & 3.00 & 7.00 & 3.00 & 5.00 & 5.00 & 3.00 & 3.00 & 5.00 & 5.00 & 7.00 & 7.00 & 3.00 & 1.00 & 3.00 & 3.00 & 1.00 & 3.00 & 1.00 & 3.00 & 9.00 & 3.00 & $7.00 \quad 5.00$ & 4.083 \\
\hline & 7.00 & 9.00 & 1.00 & 3.00 & 3.00 & 1.00 & 7.00 & 3.00 & 3.00 & 5.00 & 5.00 & 7.00 & 3.00 & 3.00 & 5.00 & 7.00 & 7.00 & 3.00 & 5.00 & 3.00 & 7.00 & 7.00 & 3.155 \\
\hline
\end{tabular}

Fig. 3. The mean difference between total perceived risk and the amount of perceived risk that is predicted by neural network

Table 6. Hypothesis examination result

\begin{tabular}{|c|c|c|c|c|c|}
\hline Hypothesis & & $\begin{array}{l}\text { Non-standardized } \\
\text { coefficients }\end{array}$ & $\begin{array}{l}\text { Standardrate } \\
\text { (for comparison) }\end{array}$ & T-Value & $\begin{array}{l}\text { Result of } \\
\text { hypothesis }\end{array}$ \\
\hline Sub-hypothesis 1.1 & $\begin{array}{l}\text { Consumers' performance risk } \\
\text { perception-total risk perception }\end{array}$ & $0 / 10$ & $0 / 15$ & $2 / 92$ & Not rejected \\
\hline Sub-hypothesis 1.2 & $\begin{array}{l}\text { Consumers' security risk } \\
\text { perception-total risk perception }\end{array}$ & $0 / 4$ & $0 / 34$ & $6 / 33$ & Not rejected \\
\hline Sub-hypothesis 1.3 & $\begin{array}{l}\text { Consumers' Social risk } \\
\text { perception-total risk perception }\end{array}$ & $0 / 05$ & $0 / 03$ & $0 / 69$ & Not accepted \\
\hline Sub-hypothesis 1.4 & $\begin{array}{l}\text { Consumers' Time loss risk } \\
\text { perception-total risk perception }\end{array}$ & $0 / 28$ & $0 / 19$ & $3 / 39$ & Not rejected \\
\hline Sub-hypothesis 1.5 & $\begin{array}{l}\text { Consumers' privacy risk } \\
\text { perception-total risk perception }\end{array}$ & $0 / 39$ & $0 / 35$ & $4 / 5$ & Not rejected \\
\hline Hypothesis 1 & $\begin{array}{l}\text { Consumers' total risk perception } \\
\text { - adoption of online banking services }\end{array}$ & $-17 / 46$ & $-0 / 51$ & $-6 / 27$ & Not rejected \\
\hline Hypothesis 2 & $\begin{array}{l}\text { Consumers' risk perception } \\
\text { - online banking services }\end{array}$ & $-17 / 46$ & $-0 / 51$ & $-8 / 27$ & Not rejected \\
\hline Hypothesis 3 & $\begin{array}{l}\text { Consumer's innovation adoption } \\
\text { - online banking services }\end{array}$ & $4 / 59$ & $0 / 12$ & $2 / 05$ & Not rejected \\
\hline Hypothesis 4 & $\begin{array}{l}\text { Consumer's innovation adoption- } \\
\text { perceived risk of online banking services }\end{array}$ & $-0 / 09$ & $-0 / 08$ & $1 / 39$ & Not accepted \\
\hline
\end{tabular}

Table 7. Fitting indexes amounts

\begin{tabular}{lll}
\hline Index & The base amount & The calculated amount \\
\hline RMSEA & $\leq 0 / 08$ & $0 / 072$ \\
NFI & $\geq 0 / 9$ & $0 / 9$ \\
NNFI & $\geq 0 / 9$ & $0 / 91$ \\
CFI & $\geq 0 / 9$ & $0 / 93$ \\
\hline
\end{tabular}

Table 8. Rating of perceived risk dimensions

\begin{tabular}{lll}
\hline Construct & Important priority & $\begin{array}{l}\text { Standardized } \\
\text { coefficients }\end{array}$ \\
\hline Perceived privacy risk & 1 & $0 / 35$ \\
Perceived security risk & 2 & $0 / 34$ \\
Perceived time loss risk & 3 & $0 / 19$ \\
Perceived performance risk & 4 & $0 / 15$ \\
Perceived social risk & 5 & $0 / 03$ \\
\hline
\end{tabular}

Thereafter, perceived security risk, perceived time loss risk and perceived performance risk should be in focus. It seems that perceived social risk has the least importance among all.

\subsection{Prediction of Others' Behavior}

One of the objectives of this study is to predict the extent of other people's perceived risk; one can forecast this by application of a neural network. Clementine software can be helpfulin running aneural network. In order to predict people perceived risk, the study sample is asked to answer a special question at the end of the questionnaire. In that question, they are asked to consider all the questions and then see 
whether they prefer online banking services or brick and mortal branches. After that, it is possible to ask a new person to answer the questionnaire that the last question is removed from. A neural network can be used to predict the extent of this new person's perceived risk. The result of using a neural network for 12 persons that are randomly selected from the study sample is shown in Fig. 3.

The two last columns show the real total perceived risk and the total perceived risk that is calculated by using neural network. It is clear that the mean difference between real answers to the last question and the amount of perceived risk that is predicted by neural network is not a lot. So, the neural network can be used to predict the amount of perceived risk of other people that are not among the current study sample with confidence.

\section{CONCLUSION}

One topic that has always attracted researchers is the investigation of the factors influencing the extent of new goods or services usage from customers. Perceived risk and innovation adoption are two variables that have got a lot of attention in this domain. The study also seeks to examine the impact of customers' risk perception and innovation adoption on the use of online banking services. In this regard, different hypothesis are made. The results of the testsindicate that the effect of consumers' social risk perception on adoption of online banking services is not acceptable. Also, it is not acceptable to say that consumer's innovation adoption affects perceived risk of online banking services adoption. But consumers' performance risk perception, security risk perception, time loss risk perception, privacy risk perception and innovation adoption affect adoption of online banking services in this study. Since it has been cleared that total perceived risk can affect the adoption of Mellat bank's online banking services in Iran, rating of perceived risk dimensions can help authorities to make the correct decisions to decrease the perceived risk and expand the adoption of online banking services as a result. The results show that the most important factor that could reduce the total perceived risk is perceived privacy risk. Besides, it is shown that using a neural network can be helpful to predict the amount of perceived risk of other people that are not among the current study sample.

\subsection{Suggestions for Future Research}

It seems that extending this model to other devices, such as electronic banking cards, ATMs, telephone banking, mobile banking and checking the results can be helpful. On the other hand, investigating relation of other factors such as legal infrastructure, communications, culture and technology on the willingness of customers to use online banking can bring remarkable results. It is proposed to add new variables to the model of the study or use it in other different banks. Such practice makes it possible to compare results with the results of current study. Banks can use these results in their policy making in order to increase the possibility of their succession.

\section{REFERENCES}

Bauer, K. and S.E. Hein, 2006. The effect of heterogeneous risk on the early adoption of Internet banking technologies. J. Bank. Finance, 30: 17131725. DOI: 10.1016/j.jbankfin.2005.09.004

Bauer, R.A., 1960. Consumer behavior as a risk taking. Proceedings of the Educator's Conference, (PEC' 60), American Marketing Association, pp: 71-83.

Beheshti, Z.F., M. Ariff, A. Jusoh, N. Zakuan and B.A. Zaidi et al., 2012. E-service quality dimensions and their effects on e-customer satisfaction in internet banking services. Proc. Social Behav. Sci., 40: 441445. DOI: 10.1016/j.sbspro.2012.03.213

Cox, D.F., 1967. Risk Handling in Consumer Behavior- An Intensive Study of two Cases. In: Risk Taking and Information Handling in Consumer Behavior, Cox, D.F. (Ed.), Harvard University, Boston, pp: 603-639.

Cunningham, L.F., J. Gerlach and M.D. Harper, 2005. Perceived risk and e-banking services: An analysis from the perspective of the consumer. J. Finance Services Market., 10: 165-178. DOI: 10.1057/palgrave.fsm. 4770183

Daniel, E., 1999. Provision of electronic banking in the UK and the republic of Ireland. Int. J. Bank Market., 17: 72-82. DOI: 10.1108/02652329910258934

Dowling, G.R. and R. Staelin, 1994. A model of perceived risk intended risk-handling activity. J. Consumer Res., 21: 119-134.

Farquhar, P.H., 1994. Strategic challenges for branding. Market. Manage., 3: 8-15.

Farzianpour, F., H. Dargahi, S. Hosseini, S.S. Hosseini and S. Hosseini, 2011a. Program evaluation of health care management: Is it adjusted for students needs? Am. J. Econ. Bus. Admin., 3: 420-424. DOI: 10.3844/ajebasp.2011.420.424 
Farzianpour, F., S. Aghababa, B. Delgoshaei and M. Haghgoo, 2011b. Performance evaluation a teaching hospital affiliated to Tehran University of medical sciences based on baldrige excellence model. Am. J. Econ. Bus. Admin., 3: 277-281. DOI: 10.3844/ajebasp.2011.272.276

Grewal, D., J. Gotlieb and H. Marmorstein, 1994. The moderating effects of message framing and source credibility on the price-perceived risk relationship. J. Consumer Res., 21: 145-153. DOI: 10.1086/209388

Haubrich, J.G. and J.A.C. Santos, 2005. Banking and commerce: A liquidity approach. J. Bank. Finance, 29: 271-294. DOI: 10.1016/j.jbankfin.2004.05.005

Hong, Z. and L. Yi, 2012. Research on the influence of perceived risk in consumer on-line purchasing decision. Phys. Proc., 24: 1304-1310. DOI: 10.1016/j.phpro.2012.02.195

Huang, D.L., P. L.P. Rau and G. Salvendy, 2010. Perception of information security. Behav. Inform. Technol., 29: 221-232. DOI: 10.1080/01449290701679361

Huang, D.L., P.L.P. Rau, G. Salvendy, G. Fei and Z. Jia, 2011. Factors affecting perception of information security and their impacts on IT adoption and security practices. Int. J. Hum. Comput. Stud., 69: 870-883. DOI: 10.1016/j.ijhcs.2011.07.007

Kolodinsky, J.M., J.M. Hogarth and M.A. Hilgert, 2004. The adoption of electronic banking technologies by US consumers. Int. J. Bank Market., 22: 238-259. DOI: 10.1108/02652320410542536

Lee, H., H. Park and J. Kim, 2013b. Why do people share their context information on social network services? A qualitative study and an experimental study on users' behavior of balancing perceived benefit and risk. Int. J. Hum. Comput. Stud., 71: 862-877. DOI: 10.1016/j.ijhcs.2013.01.005

Lee, J.H., W.G. Lim and J.I. Lim, 2013a. A study of the security of internet banking and financial private information in South Korea. Math. Comput. Modell., 58: 117-131. DOI: 10.1016/j.mcm.2012.07.019

Lee, M.C., 2009. Factors influencing the adoption of internet banking: An integration of TAM and TPB with perceived risk and perceived benefit. Electron. Commerce Res. Applic., 8: 130-141. DOI: 10.1016/j.elerap.2008.11.006

Li, S.S.C., 2013. Lifestyle orientations and the adoption of Internet-related technologies in Taiwan. Telecommun. Policy, 37: 639-650. DOI: 10.1016/j.telpol.2012.12.009

Li, Y., 2012. Theories in online information privacy research: A critical review and an integrated framework. Decision Support Syst., 54: 471-481. DOI: $10.1016 /$ j.dss.2012.06.010
Littler, D. and D. Melanthiou, 2006. Consumer perceptions of risk and uncertainty and the implications for behavior towards innovative retail services: The case of internet banking. J. Retail. Consumer Services, 13: 431-443. DOI: 10.1016/j.jretconser.2006.02.006

Mitchell, V.W., 1999. Consumer perceived risk: Conceptualizations and models. Eur. J. Market., 33: 163-195.

Mitra, K., M.C. Reiss and L.M. Capella, 1987. An examination of perceived risk, information search and behavioral intentions in search, experience and credence services. J. Serv. Mark, 13: 208-228. DOI: 10.1108/08876049910273763

Nicolaou, A.I., M. Ibrahim and E.V. Heck, 2013. Information quality, trust and risk perceptions in electronic data exchanges. Decision Support Syst., 54: 986-996. DOI: 10.1016/j.dss.2012.10.024

Ruiz-Mafe, C., S. Sanz-Blas and J. Manzano, 2009. Drivers and barriers to online airline ticket purchasing. J. Air Transport Manage., 15: 294-298. DOI: 10.1016/j.jairtraman.2009.02.001

Shin, D.H., 2010. Ubiquitous computing acceptance model: End user concern about security, privacy and risk. Int. J. Mob. Commun., 8: 169-186. DOI: 10.1504/IJMC.2010.031446

Stone, R.N. and F.W. Winter, 1987. Risk: Is it still uncertainty times consequences? Proceedings of the American Marketing Association, Winter Educators Conference, (WEC' 87), Chicago, pp: 261-255.

Vize, R., J. Coughlan, A. Kennedy and F. EllisChadwick, 2013. Technology readiness in a B2B online retail context: An examination of antecedents and outcomes. Indus. Market. Manage., 40: 909918. DOI: 10.1016/j.indmarman.2013.05.020

WB, 2013. Development grant facility financed programs. World Bank.

Wu, Y., T. Lau, D.J. Atkin and C.A. Lin, 2012. A comparative study of online privacy regulations in the U.S. and China. Telecommun. Policy, 35: 603616. DOI: 10.1016/j.telpol.2011.05.002

Yoon, C., 2010. Antecedents of customer satisfaction with online banking in China: The effects of experience. Comput. Hum. Behav., 26: 1296-1304. DOI: 10.1016/j.chb.2010.04.001

Yousafzai, S.Y., J.G. Pallister and G.R. Foxall, 2003. A proposed model of e-trust for electronic banking. Technovation, 23: 847-860. DOI: 10.1016/S01664972(03)00130-5 